\title{
Impact of Foliage on the Drag Force of Vegetation in Aquatic Flows
}

\author{
C. A. M. E. Wilson ${ }^{1}$; J. Hoyt ${ }^{2}$; and I. Schnauder ${ }^{3}$
}

\begin{abstract}
The objective of this study was to determine the contribution of a plant's foliage to the total plant's hydrodynamic drag. Experiments were conducted in a laboratory flume using samples of vegetation with different physical forms and biomechanical properties: Branches of pine (Pinus sylvestris) and ivy stipes (Glechoma hederacea). The drag force was measured directly using a strain gauge technique and determined for a series of velocities for each vegetation species with and without foliage. Experimental results revealed a distinct contribution of foliage to the total plant drag. For both plant types, this was particularly marked at lower velocities where the foliage is not streamlined and compressed and, hence, the frontal projected area of the plant is at a maximum. It was found that the flexibility of the plant's foliage and its ability to streamline with the flow may reduce the overall drag considerably. There was a distinct difference in the $C_{d} A_{P}$ parameter-velocity squared relationship between the "with" foliage plants and nonfoliage counterparts due to the streamlining effect of the foliage with the flow and, hence, the reduction in overall drag associated with the new compressed plant form.
\end{abstract}

DOI: 10.1061/(ASCE)0733-9429(2008)134:7(885)

CE Database subject headings: Vegetation; Aquifiers; Flumes; Velocity; Sediment transport; Rivers; Restoration.

\section{Introduction}

Vegetation-flow interactions are central to many problems of practical interest to hydrologists and hydraulic engineers including flood risk studies, sediment transport studies, and the design of river restoration schemes. It has been standard practice in hydraulic modeling not to make a distinction between bed shear stress associated with a grain size or bed roughness and hydrodynamic drag induced by obstacles such as vegetation or bridge piers, which project through a significant degree of the water column. This lack of distinction is appropriate for 1D modeling methods where the use of a bulk energy loss coefficient such as Darcy-Weisbach friction factor expresses the balance between the longitudinal component of the weight of the water volume and the overall resistance to the flow. These modeling approaches are suitable and appropriate for reach-scale modeling applications such as the prediction of flood inundation extent where the accurate prediction of water surface elevation is paramount and the computation of velocity less so. However, for the prediction of flow dynamics and geomorphology, 2D and 3D approaches enable us to represent the normal stresses induced by bed roughness and vegetation obstructions separately and in different ways,

\footnotetext{
${ }^{1}$ Senior Lecturer and Director of the Eco-hydraulics Group, Hydroenvironmental Research Centre, School of Engineering, Cardiff Univ., CF24 3AA, U.K.

${ }^{2}$ Visiting Fellow, Dept. of Civil Engineering, Univ. of Bristol, BS8 1TR, U.K.

${ }^{3}$ Postdoctoral Research Fellow, Leibniz Institute for Freshwater Ecology and Inland Fisheries, Müggelseedamm 310, D-12587 Berlin, Germany.

Note. Discussion open until December 1, 2008. Separate discussions must be submitted for individual papers. To extend the closing date by one month, a written request must be filed with the ASCE Managing Editor. The manuscript for this paper was submitted for review and possible publication on June 6, 2006; approved on October 9, 2007. This paper is part of the Journal of Hydraulic Engineering, Vol. 134, No. 7, July 1, 2008. @ASCE, ISSN 0733-9429/2008/7-885-891/\$25.00.
}

through a roughness height and drag force representation (Stoesser et al. 2003; Wilson et al. 2006), therefore, allowing the velocity field to be characterized within the water depth or over the river section, which is crucial in these types of applications.

In determining the hydraulic resistance for vegetation, we need to account for the peculiarities associated with vegetation such as its permeable, heterogeneous nature and its ability to bend and change shape under flow action. Kouwen et al. (1969) was one of the first to recognize the effect of plant flexibility on hydraulic resistance. In characterizing the velocity profile for flexible vegetated covers, the intercept and gradient were evaluated from plots of normalized velocity against the natural logarithm of the relative roughness (flow depth divided by the deflected height) for a series of vegetation covers. Kouwen et al. postulated that the intercept and gradient for each cover were functions of the vegetation density and flexibility and proposed that relationships between these coefficients and the physical properties such as vegetation stiffness and density should be determined.

Nepf (1999) examined the hydraulic resistance of vegetation density and extended the drag force cylinder-based model for a single stem to a stem density. This approach focused on rigid, impermeable, emergent stems. A bulk drag coefficient was used to account for the wake generation, wake interaction between stems, and the associated reduction in the velocity for downstream stems.

Drag force exerted by a single flexible plant has been measured directly in a number of ways. Most methods use a load cell, whereby its change in resistance due to a displacement (compression or extension) is related to a force. Methods vary in the manner by which the plant is linked to the load cell. One of the main challenges in designing such a system is to keep the frictional force of the system and its component parts to a minimum relative to the magnitude of the drag force exerted by the vegetation.

Probably one of the most in-depth studies in terms of the range of velocities examined, determination of plant streamlining area and scale of experiments, was conducted by Oplatka (1998). Oplatka measured the drag on willow trees (Salix purpurea and 
Salix viminalis), which were up to five years old and whose heights ranged from $1.8-4.5 \mathrm{~m}$. The trees were collected during the summer and had leaves. The experiments were carried out by mounting the willows in their upright position on a pivoting frame, which was attached to flume rails. The frame was then pulled with constant velocity through a $140 \mathrm{~m}$ long towing tank and flow velocities of up to $4 \mathrm{~ms}^{-1}$ were examined. Oplatka believed that maximum streamlining (where there is no further reduction in frontal area) occurred at velocities greater than this value. Oplatka quantified the degree of plant streamlining through examining the lateral, longitudinal, and height compression of the plants and found that the frontal occupied area, computed from the compressed plant width multiplied by the compressed height, decreased by $15-30 \%$ at a flow velocity of $1 \mathrm{~ms}^{-1}$ and to approximately $5 \%$ at a flow velocity of $4 \mathrm{~ms}^{-1}$. The decrease in frontal area with increasing velocity resulted in a relatively smaller increase in the rate of change in drag with increasing velocity. This influenced the drag-velocity relationship significantly and tended towards a linear rather than a squared function.

Freeman et al. (2000) performed extensive drag force experiments on 10 different plant types. The plant stipe was attached to a horizontal aluminium plate fixed on bearings to the flume bed. At the downstream end of the plate, a load cell was attached horizontally and the compression force was determined from the load cell. The plate was covered with a plastic lid to reduce frictional drag of the bearings against the plate. The impact of foliage on the generated drag force was examined. Freeman et al. observed a critical point at which the plant reached maximum streamlining, where the rate of change in frontal projected area with increasing velocity is zero. A linear relationship between drag and velocity was observed before the maximum point of streamlining was reached.

James et al. (2004) used a pivoting frame system whereby the plant stipe was fixed to the lower end of a rectangular frame on a pivoting system. The force required to counter balance the rotation of the frame under the influence of drag was then determined. Tests were conducted in a flume of width $0.915 \mathrm{~m}$ on two species of reed stems in their emergent condition (Phragmites australis and Typha capensis). The foliage of one of the samples of $P$. Australis was progressively removed over a series of experiments; however, the impact of the reduced area on the magnitude of the generated drag force and the resulting drag coefficient were not presented.

Armanini et al. (2005) determined the drag force of willow trees (Salix alba), which were mounted in a vertical cylinder attached to two horizontal parallel plates that sat on the flume bed. Strain gauges were attached to the plates' corners enabling the relative horizontal and vertical upper plate's movement to the lower plate's movement to be measured. Experiments were conducted with and without leaves and at mean flow velocities of up to $0.8 \mathrm{~ms}^{-1}$.

In this paper, we report on a series of experiments that were conducted on plants of two species (Pinus sylvestris and Glechoma hederacea) in their emergent condition. The objective of this study is to determine the effective contribution of a plant's foliage to the total plant's hydrodynamic drag. A method for drag force determination was realized in which the drag force on a single plant branch or stipe is measured directly by two strain gauges set into the base of the vegetal branch embedded into the channel bed. The species chosen differed in their biomechanical properties, plant form, and foliage type. For each specimen, the impact of foliage is examined in terms of the drag force ratio and Manning-Strickler's coefficient.

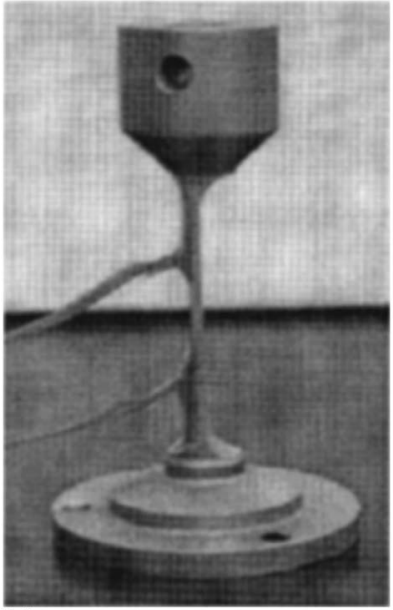

(a)

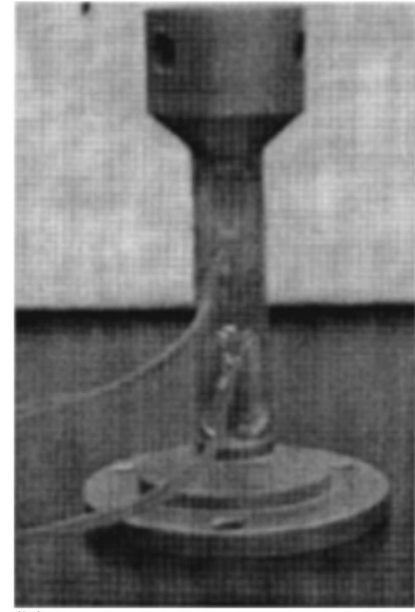

(b)
Fig. 1. Drag force measurement using a cantilever technique where the upper cup retains plant stem (a) profile of cantilever showing strain Gauges 1 and 2; (b) frontal view of cantilever and strain gauges; when placed in flume bed, this view is in the downstream flow direction

\section{Experimental Setup}

Experiments were performed in a glass-walled flume $300 \mathrm{~mm}$ wide, $300 \mathrm{~mm}$ deep, and $10 \mathrm{~m}$ long. The longitudinal bed slope was fixed at 1 in 1,000 to be representative of U.K. lowland river corridors. The flow depth along the flume was measured with pointer gauges while the discharge was measured using an impeller flow meter to an accuracy of $\pm 0.01 \mathrm{l} / \mathrm{s}$. The flow rate was varied; however, a flow depth of $160 \mathrm{~mm}$ was maintained in the vicinity of the working section for all experiments. This enabled the area mean velocity to be varied while the flow depth and depth of plant in contact with the water column remained constant. The area mean velocity was determined through known values of flow rate and the cross-sectional flow area, and will be referred to hereafter as the velocity. Plant branches and stipes of length $200 \mathrm{~mm}$ were used in all experimental series. The branches and stipes were emergent (projected through the water surface).

A drag-force measurement system was developed whereby the stem of the plant sapling was directly fixed at its base to a short stainless steel beam, which was embedded into the flume base (see Figs. 1 and 2). Two strain gauges were set into the beam at a precise distance apart [Eq. (1)]. When subjected to flows, this enabled the plant to act as a cantilever in bending. Using one strain gauge enabled the magnitude of the bending moment to be measured; however, the distance of the drag force from the strain gauge remained unknown and, hence, the drag force cannot be determined. Using two strain gauges enabled both the drag force and the length of the lever arm $(L)$ to be determined through

$$
\begin{gathered}
L=l\left(\frac{M_{1}}{M_{2}-M_{1}}\right) \\
F_{D}=\frac{M_{1}-M_{2}}{l}
\end{gathered}
$$

where $M_{1}$ and $M_{2}=$ bending moments at Gauges 1 and 2 (see Figs. 1 and 2).

Velocities in the range of $0.25-0.65 \mathrm{~ms}^{-1}$ were examined. The lower limit was dictated by the noise from the strain gauge setup, 


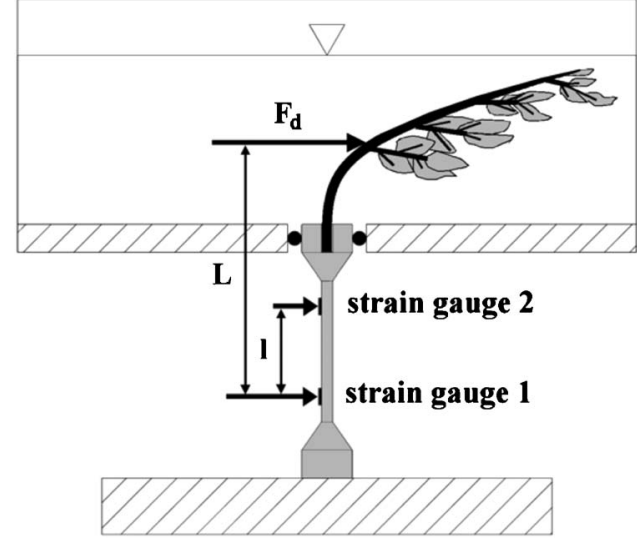

Fig. 2. Drag force measurement system

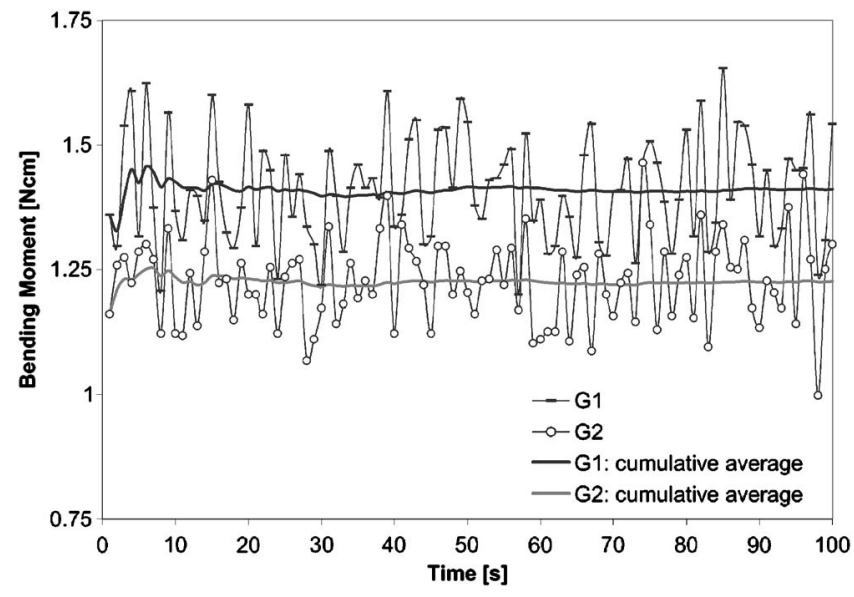

Fig. 3. (a) Variation of instantaneous bending moment measurements as a function of time; the cumulative average is shown for Gauges 1 (G1) and 2 (G2), together with the resulting drag force

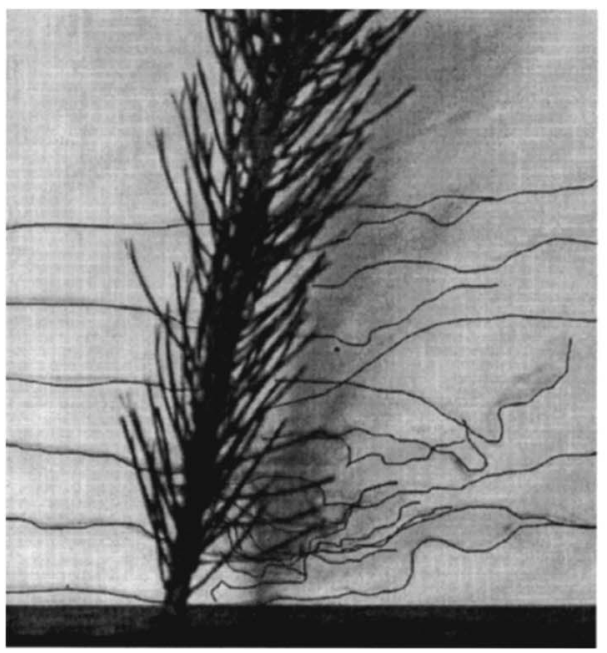

while the upper limit was dictated by the point at which surface waves are generated in the flume. The sampling frequency of the strain measurements was $1 \mathrm{~Hz}$ and a sampling period of $50 \mathrm{sec}$ was used for each experimental series. The sampling period was determined by examining a time series of strain gauge measurements. The time-averaged drag force was evaluated from the 50 measurements; for this sampling period, the cumulative timeaveraged value fluctuates by less than $0.1 \%$ from the timeaveraged value corresponding to a $100 \mathrm{sec}$ sampling period (see Fig. 3).

While it is acknowledged that ivy (Glechoma hederacea) is not a principal plant associated with the riparian corridor, this study aimed to examine the contribution of foliage and its form to the total drag exerted by a plant. Pine (Pinus sylvestris) and ivy plants (Glechoma hederacea) offered a means of comparing and contrasting simplified plant foliage structures (see Fig. 4) that display features that are intrinsic to riparian plants. The pine samples were composed of a woody branch that was covered densely both around the circumference and along the branch height with needles of small individual area. The needles generally were relatively rigid in nature and generally projected upwards at the flow velocities examined. Contrastingly, the ivy samples were composed of a woody branch with leaves located every $20-30 \mathrm{~mm}$ along the height of the branch. The leaves are much larger in area than individual needles of the pine samples and streamlined with the flow at the velocities examined. Both the pine and ivy test samples were chosen based on similarity of their stem diameter.

\section{Methodology and Nondimensionalization}

The drag force on a flexible obstruction is dynamic; the drag force exerted by the plant changes as it bends and streamlines with the flow. The frontal projected area of a flexible plant is a variable that is dependent on the flow velocity and the plant properties. As mentioned earlier, Oplatka (1998) examined the degree of plant streamlining and plant compression as a function of velocity for willow trees. However, it is technically difficult to determine the variation in frontal projected area for all plant species under all flow conditions. For this reason, in this study as in previous stud-

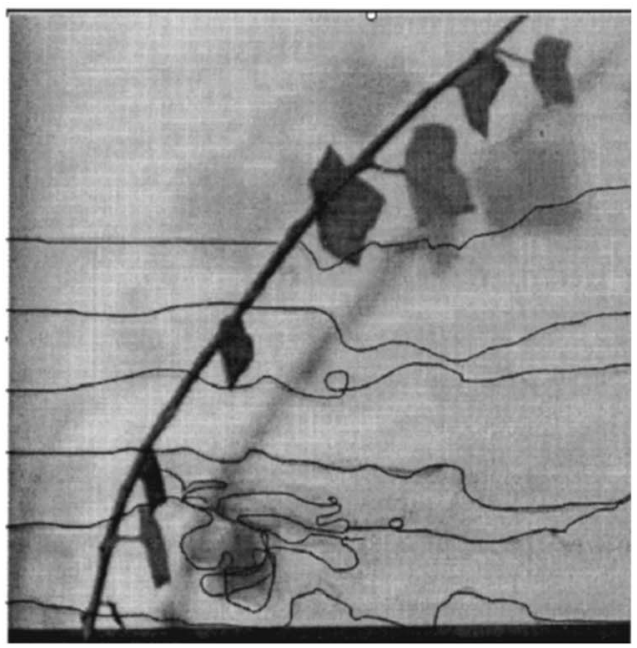

Fig. 4. Photographs of (a) pine; (b) ivy specimens taken from the flume sidewall. A turbulent flow tracer (Hoyt and Sellin 1995) was used to visual the flow field. 
Table 1. Effective Frontal Projected Area of Various Vegetation Determined in Still Air, under No Flow Action

\begin{tabular}{|c|c|c|c|}
\hline Vegetation type & $\begin{array}{l}\text { Sample } \\
\text { number }\end{array}$ & $\begin{array}{c}A_{\text {effective foliage }} \\
\left(\mathrm{m}^{2}\right)\end{array}$ & $\begin{array}{l}A_{\text {effective }} \\
\text { ratio }\end{array}$ \\
\hline Ivy stem & 1 & 0.0062 & 9.492 \\
\hline Ivy stem & 2 & 0.0054 & 8.245 \\
\hline Pine stem & 1 & 0.0048 & 4.959 \\
\hline Pine stem & 2 & 0.0050 & 5.236 \\
\hline $\begin{array}{l}\text { Willow tree } \\
\text { (Armanini et al. 2005) }\end{array}$ & 1 & 0.1041 & 1.286 \\
\hline $\begin{array}{l}\text { Willow tree } \\
\text { (Armanini et al. 2005) }\end{array}$ & 2 & 0.0971 & 1.284 \\
\hline $\begin{array}{l}\text { Willow tree } \\
\text { (Armanini et al. 2005) }\end{array}$ & 3 & 0.1127 & 1.276 \\
\hline $\begin{array}{l}\text { Group of willow trees, } \\
11 \text { trees per } m^{2} \text { (Järvelä 2002) }\end{array}$ & $\mathrm{n} / \mathrm{a}$ & & $25^{\mathrm{a}}$ \\
\hline
\end{tabular}

ies (Armanini et al. 2005), the effective frontal projected area of the vegetation was determined in still air and not under flow action. For a plant assemblage, the area of the foliage and woody parts was found individually and then summed. The area of the woody part of the vegetation was determined directly from digital photographs and image processing software. The foliage was removed from the plants and laid flat on a digital scanner, after which image processing software was employed. These areas, when summed, are referred to as $A_{\text {effective. }}$ This is the maximum possible frontal area of the plant. We use $A_{\text {effective }}$ only as a reference area to enable both the area of foliage to total plant area to be evaluated and for comparison with other studies (see Table 1).

The $C_{d} A_{p}$ parameter, which is computed directly from the drag force and velocity measurements, combines the classical drag coefficient with the "wet" frontal projected plant area and allows this problem to be overcome. The $C_{d} A_{p}$ parameter is defined as

$$
C_{d} A_{P}=\frac{2 F_{D}}{\rho U^{2}}
$$

where $F_{D}=$ drag force. In assessing the contribution of the foliage to the total plant drag, the ratio of the drag forces for the "with" foliage plant to the "nonfoliage" plant can be evaluated. Since the drag force is directly proportional to the $C_{d} A_{p}$ parameter, for a given velocity, the ratio between the $C_{d} A_{p}$ parameter for the "with" foliage to the nonfoliage plant is exactly the same parameter as the drag force ratio

$$
F_{D} \text { ratio }=\frac{F_{D} \text { with foliage }}{F_{D} \text { without }}=C_{d} A_{P} \text { ratio }=\frac{C_{d} A_{P} \text { with foliage }}{C_{d} A_{P} \text { without }}
$$

If the shear force attributed by the flume's bottom and sides is negligible relative to the drag force of the vegetation, the shear force generated by the flume bed can be ignored. Substituting for the velocity term using the Manning-Strickler's formula then gives a relationship between the $C_{d} A_{p}$ term and the ManningStrickler's coefficient $n$

$$
n=\left(\frac{R^{4 / 3}}{2 g D B y} C_{d} A_{P}\right)^{1 / 2}
$$

This equation indicates that the ratio of Manning-Strickler's coefficient for a "with" foliage plant to nonfoliage one is directly proportional to the square root of the $C_{d} A_{p}$ ratio.

\section{Results and Discussion}

The experiments revealed a distinct contribution of foliage to the total plant drag (see Fig. 5). This was observed for both the needles of the pine branches and the foliage of the ivy. The additional drag contribution from the needles of the pine branches is particularly marked at lower velocities, whereas for the ivy plants, the additional drag contribution of the foliage shows little dependence on the velocity (see Figs. 6 and 7). For both species, the $F_{D}$ or $C_{d} A_{p}$ ratio is greater than unity for all flow velocities examined (see Fig. 7). For the pine branches, the $F_{D}$ ratio decreased with increasing velocity. This is in contrast to the ivy plants where the $F_{D}$ ratio tended towards a constant with increasing velocity (see Fig. 7). This is likely to be due to the gradual streamlining of the needles with increasing velocity where the frontal plant area is continually compressed as the velocity is increased. For the ivy
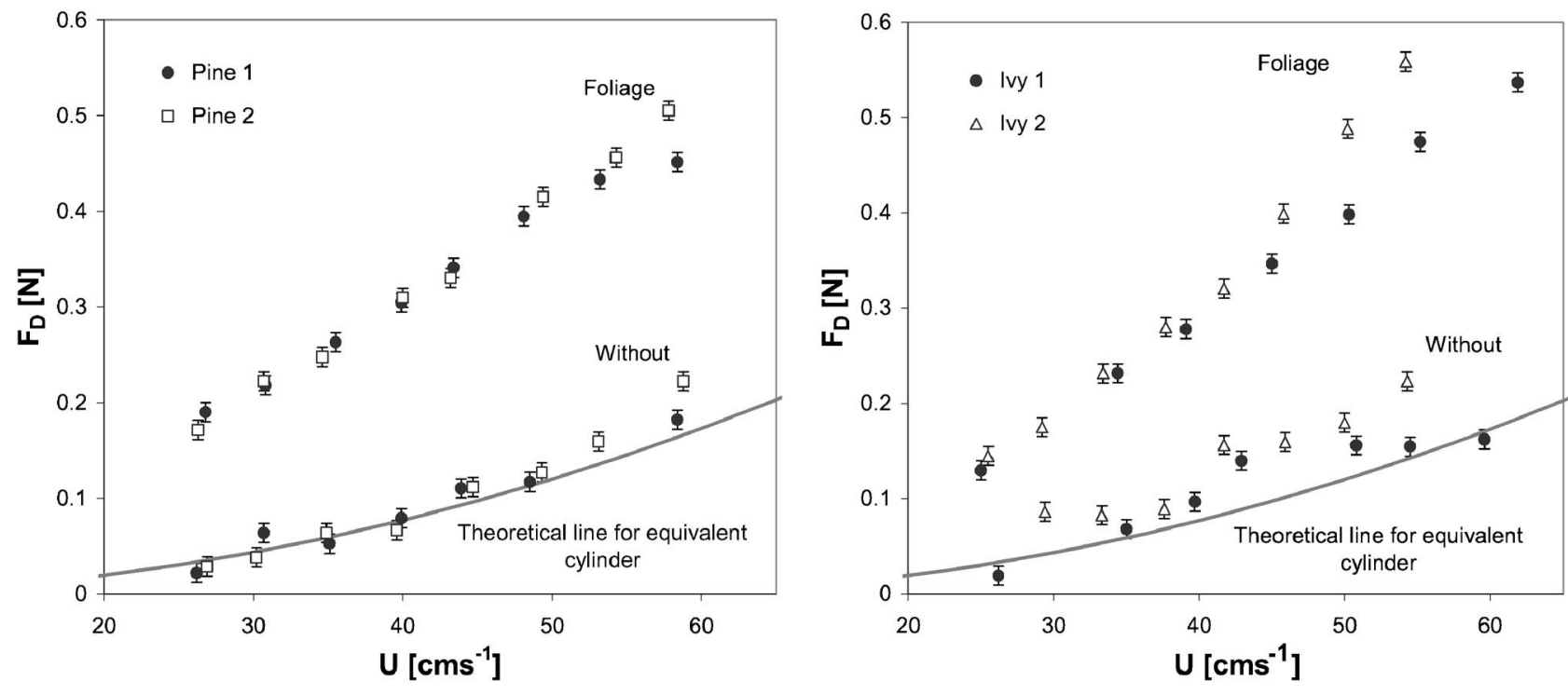

Fig. 5. Drag force-velocity relationships for pine and ivy plants with and without foliage 

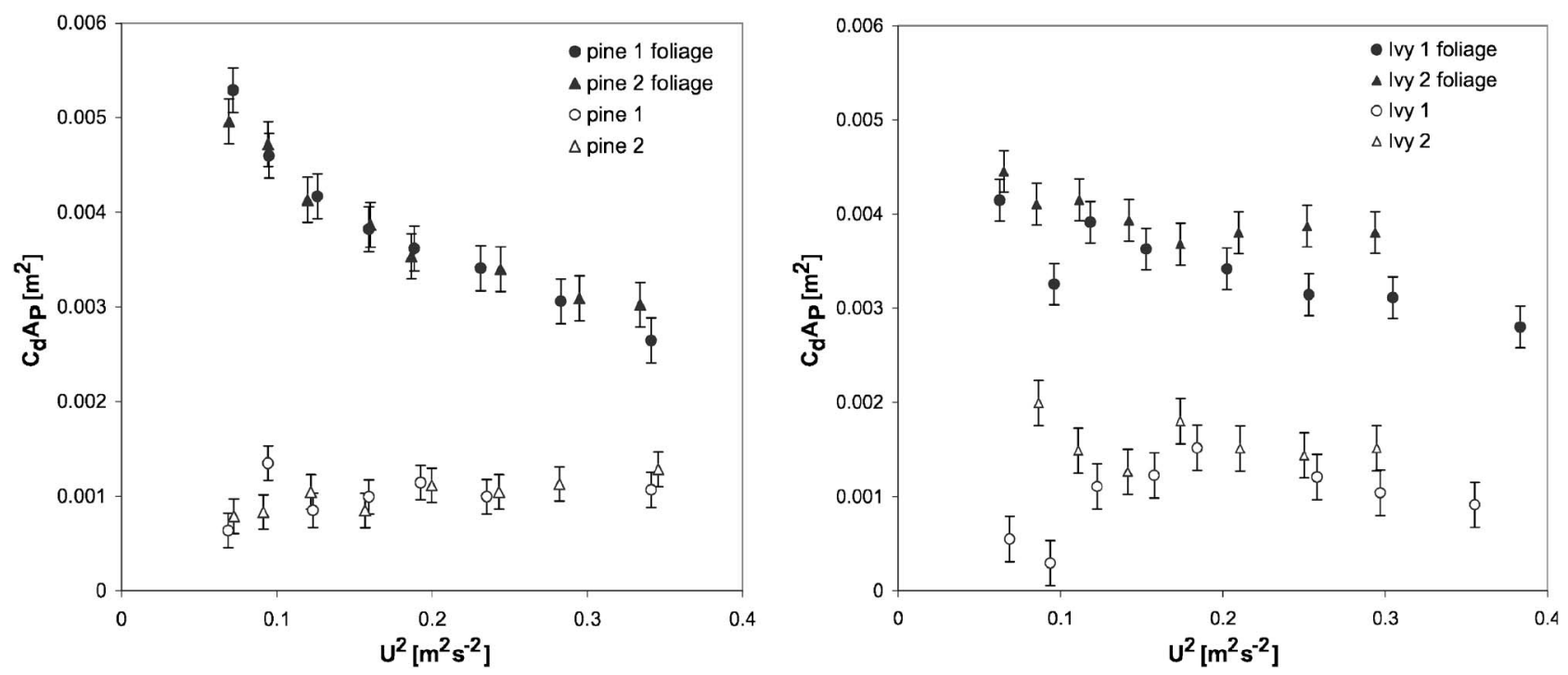

Fig. 6. Variation of parameter $C_{d} A_{P}$ with square of velocity for pine and ivy plants with and without foliage

plants, this may indicate that the foliage was becoming closer to the point of maximum streamlining at lower relative velocities than for the pine plant.

At the lower velocities examined, the $F_{D}$ ratio tends to be greater for the pine specimens than for the ivy, indicating that there is greater drag generated by the pine needles than the ivy foliage. The $F_{D}$ ratios for the pine and ivy plants are the same over the range in velocity squared $0.2-0.4 \mathrm{~m}^{2} \mathrm{~s}^{-2}$. This is an interesting observation as the $A_{\text {effective }}$ ratio for the pine specimens is nearly half of that for the ivy specimens (see Table 1). This behavior, therefore, illustrates that even though the effective frontal area of a plant's foliage may be relatively large for a particular plant species, the flexibility of the plant and its ability to streamline with flow, reduces the overall drag. Flow tracer studies (Fig. 4) show that the less flexible pine needles appear to induce more turbulence in the flow (and hence more drag) than the ivy leaves.
Thus, the flow resistance may be considerably less for a flexible plant with considerable foliage compared to a less flexible plant with minimal foliage.

For a rigid body at the range of Reynolds numbers examined in this study, the parameter $C_{d} A_{p}$ should remain constant with increasing the square of the velocity. There is a distinct difference in the $C_{d} A_{p}$ velocity squared relationship between the "with" foliage plants and nonfoliage ones; the $C_{d} A_{p}$ velocity squared relationship is fairly constant for the plants without foliage, consistent with that for a rigid body, whereas for both "with" foliage plants, decreases with increasing velocity squared until the plant foliage is fully compressed and the $C_{d} A_{p}$ parameter reaches a minimum (see Fig. 6). This contrasting behavior is due to the streamlining of the foliage with the flow and, hence, the reduction in overall drag associated with the new compressed plant form. The $C_{d} A_{p}$ velocity squared relationship for the "with" foliage plants is con-
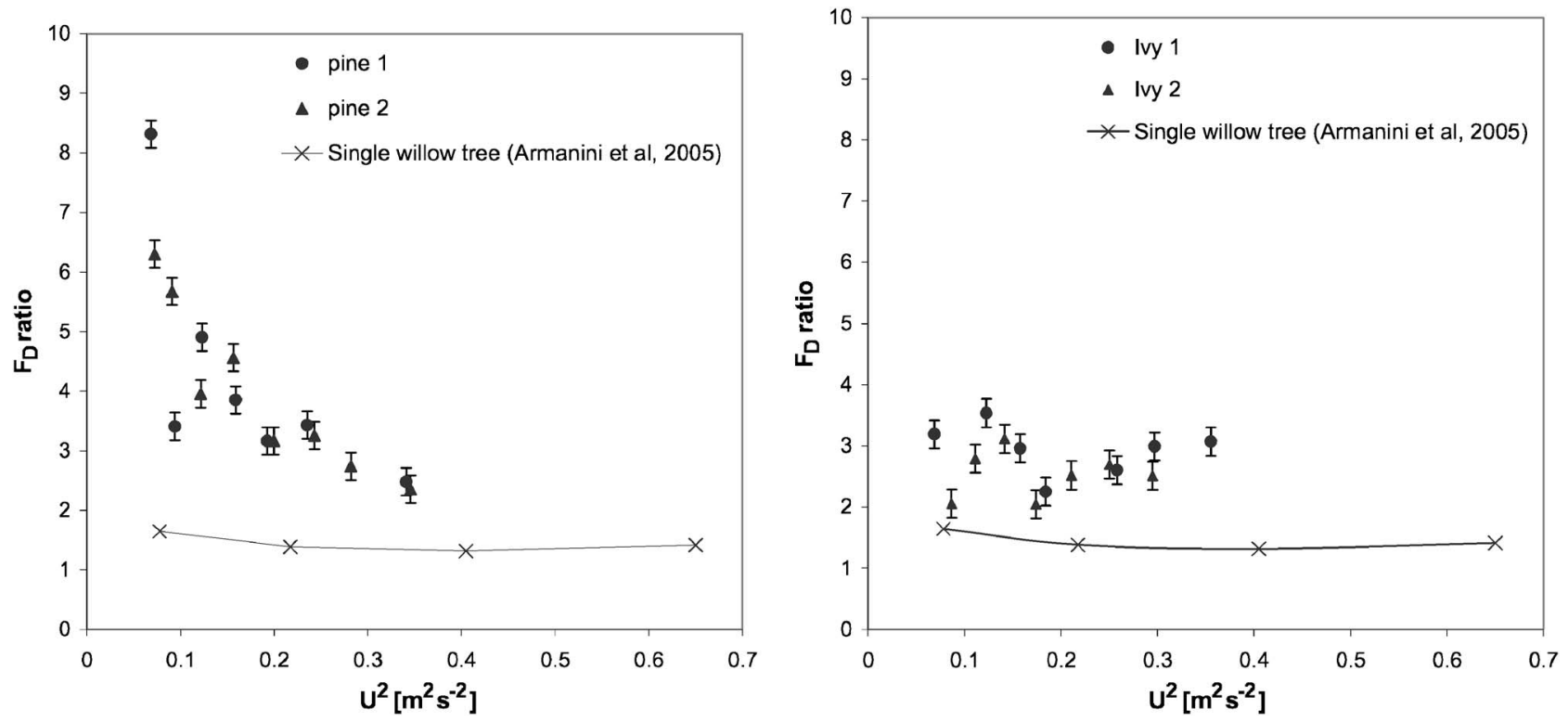

Fig. 7. Variation of the $F_{D}$ ratio with square of velocity for pine branches, ivy plants, and a willow tree with and without foliage 


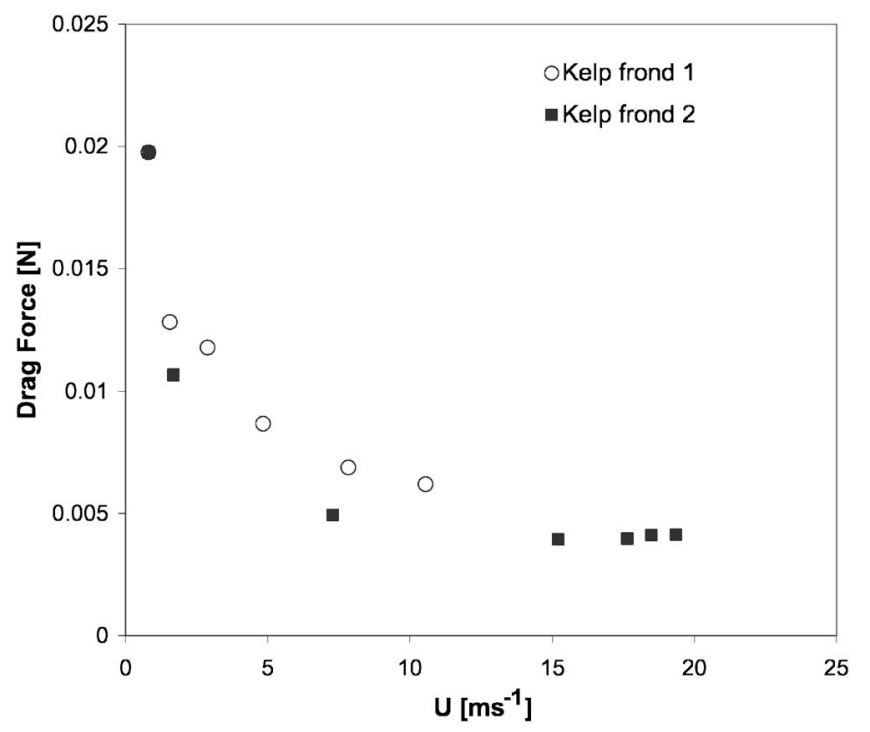

Fig. 8. Variation of parameter $C_{d} A_{P}$ with square of velocity for kelp fronds adapted from Wilson et al. (2003) and Dubi (1995)

sistent with the functional relationship observed by Oplatka (1998). Using reanalyzed data from Wilson et al. (2003), this behavior can be observed for a species of kelp (Laminaria hyperborea), where the kelp fronds were tested over a large range of velocities and to a point where the fronds are fully compressed and a minimum $C_{d} A_{p}$ value is reached (see Fig. 8). In this manner, each plant species may have a range of $C_{d} A_{p}$ velocity squared profiles that may be a property of plant height and individual nature of each plant's morphology. A minimum and maximum envelope of curves may be ascertained for each plant species, enabling for a given velocity the minimum and maximum $C_{d} A_{p}$ value and so minimum and maximum limits of drag to be estimated for a given plant species.

The $C_{d} A_{p}$ ratio has been computed for willow tree experimental data from Armanini et al. (2005); these data correspond to the "small salix" where the plant is emergent and the flow depth to plant height ratio is equal to 0.79 . These data are presented in Fig. 7. Over the same range of velocities, the contribution of the foliage to the plant's drag is less for the willow tree than for the ivy and pine plants. This is consistent with the ratio of effective frontal area of the foliage to the total effective front plant area $A_{\text {effective }}$ ratio (see Table 1); the willow trees have the lowest $A_{\text {effective }}$ ratio.

The effective impact of the plant's foliage on the ManningStrickler's coefficient is presented for single stems of ivy and pine (present study), a single willow tree (Armanini et al. 2005), and a group of willow trees (Järvelä 2002) in Fig. 9. Here, the ratio of Manning-Strickler's coefficient for a "with" foliage plant to nonfoliage one was evaluated. The ratio of Manning-Strickler's coefficient for the former two studies was computed using Eq. (5). Using data from the head loss experiments conducted by Järvelä (2002), a ratio of Manning-Strickler's coefficient was evaluated for a group of willow trees. The configuration of the trees corresponds to a density of 11 trees per $\mathrm{m}^{2}$ [spacing "Pa" Järvelä (2002)].

For all experiments, the ratio decreases with increasing velocity and is dependent on three properties: (i) The contribution of the foliage area to the overall plants projected area; (ii) the bending and streamlining characteristics of the plant for the given velocity range; and (iii) the Reynolds number. The ratio is lowest for the single willow trees used in the Armanini et al. (2005)

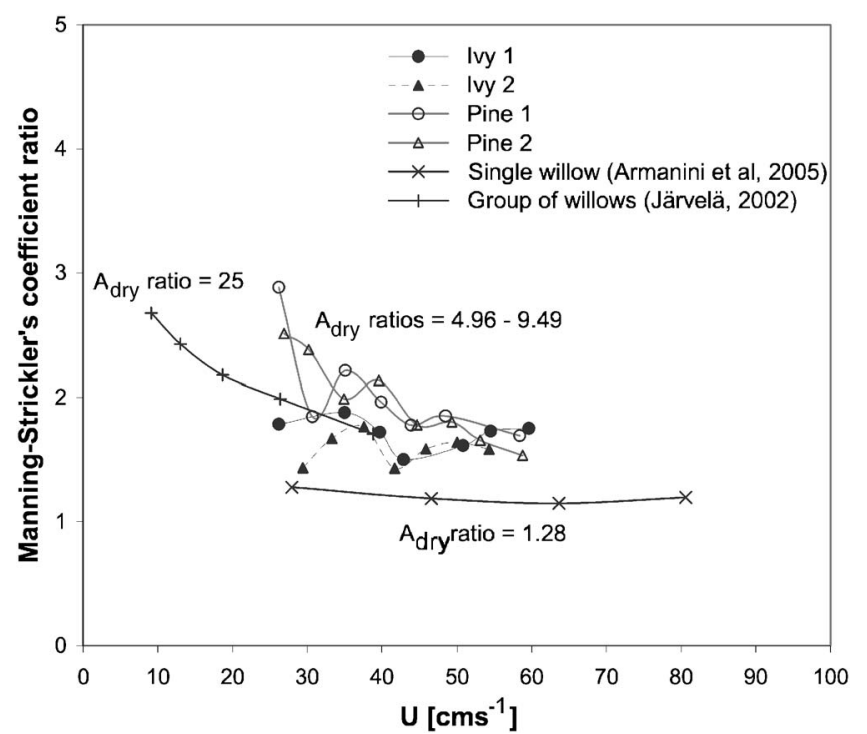

Fig. 9. Variation in the Manning-Strickler's coefficient ratio with velocity for different vegetation types

study and this is likely to be due to the low leaf area to woody area of trees used in this study (see Fig. 9 and Table 1). The Manning-Strickler's coefficient ratio varies over a similar range for the willow trees and pine and ivy stems, between 1.4-3. Undoubtedly these statements are based on limited data, however, these findings show the potential effect of seasonality on the roughness coefficient for plants and trees.

\section{Conclusions}

This study reports on a method used for quantifying directly the drag exerted on single plant specimens when subjected to different flow velocities. The experimental results presented show the effective contribution of plants' foliage to the total plants' hydrodynamic drag for the emergent condition. This is examined through direct measurement of the drag force for plants with and without foliage, and evaluation of both the effective frontal plant area under no flow action, the $C_{d} A_{p}$ ratios, and the corresponding impact of foliage on the Manning-Strickler's coefficient. The experimental results showed the following:

- A distinct contribution of foliage to the total plant's drag. For pine specimens, this was particularly marked at lower velocities where the foliage is not streamlined and compressed and, hence, the frontal projected area of the plant remains at a maximum. The contribution of the ivy foliage has little dependence on the velocity.

- Greater drag is generated at lower velocities for the pine plants with foliage than for the ivy plants with foliage compared to their nonfoliage counterparts. This indicates that the flexibility of the plant's foliage and its ability to streamline with the flow may reduce the overall drag considerably. Thus, the flow resistance of a plant may be significantly less for a flexible plant with considerable foliage compared to a less flexible plant with minimal foliage.

- There is a distinct difference in the $C_{d} A_{p}$ velocity squared relationship between the "with" foliage plants and the nonfoliage counterparts due to the streamlining of the foliage with the flow and, hence, the reduction in overall drag associated with the new compressed plant form. The $C_{d} A_{p}$ velocity 
squared profile for the "with" foliage plants is consistent with that observed by Oplatka (1998) for submerged willow trees and for a species of kelp.

- The $C_{d} A_{p}$ ratio demonstrates that the contribution of the foliage to the plant's drag is less for the willow tree examined by Armanini et al. (2005) than for the ivy and pine plants studied herein. In terms of the effective impact of foliage on the Manning-Strickler's coefficient, this corresponds to ManningStrickler's coefficient ratio of 1.2 for a single willow tree compared to 1.5-1.75 for pine and ivy plants, at a velocity of $0.5 \mathrm{~ms}^{-1}$.

This study demonstrates the effective contribution of foliage, leaves, and seasonality on the total plants' drag and its corresponding effect on hydrodynamic drag and values of a onedimensional roughness coefficient. Recently, it has been demonstrated that the hydraulic resistance of a river channel is highly variable with seasonality (Sellin and van Beesten 2004). Furthermore, climate change scenarios point to a greater frequency of flood events in the summer months. Hence, for plants and trees on floodplains, the effect of foliage could have a considerable impact on the overall hydraulic resistance and water levels. This effect needs to be addressed appropriately in computational hydraulics and in flood defense design.

\section{Acknowledgments}

C. A. M. E. Wilson was aided by the Engineering and Physical Science Research Council (EPSRC) of the U.K. on an Advanced Research Fellowship Grant No. GR/A11239/01. The writers are grateful to Julien Mas who assisted in the preliminary tests. Finally, thanks to the reviewers for providing constructive and thoughtful comments.

\section{Notation}

The following symbols are used in this paper:

$A_{\text {effective }}=$ effective frontal plant area under no flow action;

$A_{\text {effective foliage }}=$ effective frontal plant area of foliage in air where foliage is laid flat on a scanner;

$A_{\text {effective }}$ ratio $=$ ratio of effective frontal plant area of plant with foliage to effective frontal plant area of plant without foliage;

$A_{p}=$ frontal projected plant area when under flow action;

$B=$ width of channel;

$C_{d}=$ drag coefficient;

$C_{d} A_{p}=C_{d} A_{p}$ parameter;

$C_{d} A_{p}$ ratio $=$ ratio of $C_{d} A_{p}$ parameter drag force for a "with" foliage plant to a nonfoliage plant;

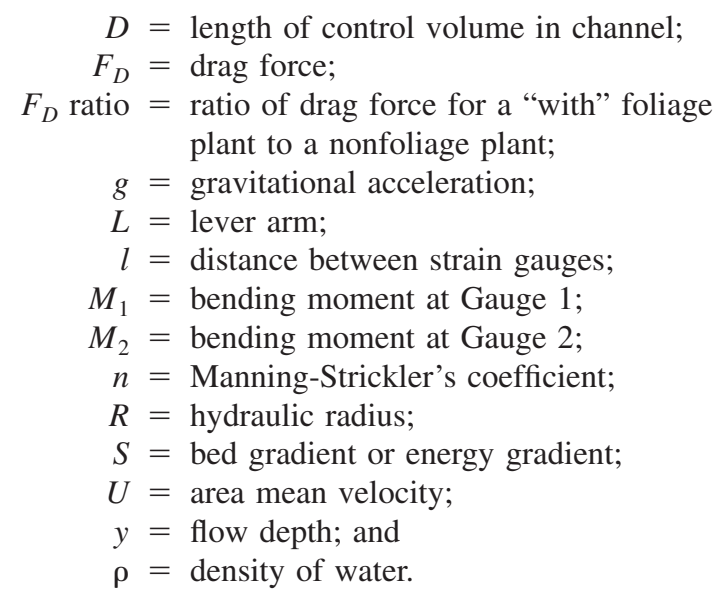

\section{References}

Armanini, A., Rignetti, M., and Grisenti, P. (2005). "Direct measurement of vegetation resistance in prototype scale." J. Hydraul. Res., 43(5), 481-487.

Dubi, A. M. (1995). "Damping of water waves by submerged vegetation: A case study on laminaria hyperborea." Ph.D. thesis, Univ. of Trondheim, Norway.

Freeman, G. E., Raymeyer, W. J., and Copland, R. R. (2000). "Determination of resistance due to shrubs and woody vegetation." Rep. No. ERDC/CHL TR-00-25, U.S. Army Corps of Engineers.

Hoyt, J., and Sellin, R. (1995). "A turbulent-flow dye-streak technique." Exp. Fluids, 20, 38-41.

James, C. S., Birkhead, A. L., Jordanova, A. A., and O'Sullivan, J. J. (2004). "Flow resistance of emergent vegetation." J. Hydraul. Res., 42(4), 390-398.

Järvelä, J. (2002). "Flow resistance of flexible and stiff vegetation: A flume study with natural plants." J. Hydrol., 269(1-2), 44-54.

Kouwen, N., Unny, T. E., and Hill, H. M. (1969). "Flow retardance in vegetated channels." J. Irrig. and Drain. Div., 95(2), 329-342.

Nepf, H. (1999). "Drag, turbulence, and diffusion in flow through emergent vegetation." Water Resour. Res., 35(2), 479-489.

Oplatka, M. (1998). "Stability and failure of willow-stabilized river banks using soil bioengineering solutions (in German)." Stabilitaet von Weidenverbauungen an Flussufern, Mitteilungen der Versuchsanstalt fuer Wasserbau, Hydrologie und Glaziologie, No. 156, ETH Zurich.

Sellin, R. H. J., and van Beesten, D. P. (2004). "Conveyance of a managed vegetated two-stage river channel." Proc., Institution of Civil Engineers, Water Management, Issue 157, 21-33.

Stoesser, T., Wilson, C. A. M. E., Bates, P. D., and Dittrich, A. (2003). "Application of a 3D numerical model to a river with vegetated floodplains." J. Hydroinform., 5, 99-112.

Wilson, C. A. M. E., Stoesser, T., Bates, P. D., and Batemann Pinzen A. (2003). "Open channel flow through different forms of submerged flexible vegetation." J. Hydraul. Eng., 129, 847-853.

Wilson, C. A. M. E., Yagci, O., Rauch, H.-P., and Olsen, R. (2006). "3D numerical modelling of a willow vegetated river/floodplain system." J. Hydrol., 327(1-2), 13-21. 